\title{
The effect of number of large reward training trials on behavior following incentive reduction'
}

\author{
STEPHEN F. DAVIS ${ }^{2}$ AND ALVIN J. NORTH, 3 SOUTHERN \\ METHODIST UNIVERSITY, Dallas, Texas
}

Three groups of rats were given 18 large reward, 108 large reward, or 108 small reward acquisition trials, respectively. Following acquisition all Ss received 63 small reward trials. This phase constituted an incentive reduction phase for $S$ s receiving large reward during acquisition. The results indicated greater disruption of performance, primarily in the start measure, during the incentive reduction phase for the Ss receiving 108 than for Ss receiving 18 large reward trials during acquisition.

Numerous investigators (Crespi, 1942; Zeaman, 1949; DiLollo, 1964 , etc.) have demonstrated "depression" effects (undershooting a small reward control group) on the part of Ss that have had incentive abruptly reduced from a large to a small amount.

One possible explanation for these results has been offered by frustration theory (Amsel, 1958). In addition to an explanation of the depression effect, there are several other inferences from frustration theory. If incentive magnitude reduction is similar to incentive withdrawal, it would follow that frustration would be greater if the down-shift in incentive occurred following a large number of training trials than if the down-shift occurred following a small number of training trials. This would be expected because of stronger conditioning of $\mathrm{rg}_{\mathrm{g}} \mathrm{g}$, as the number of reward trials increases, and therefore a stronger elicitation of $\mathrm{r}_{\mathrm{f}}-\mathrm{sf}$ upon the receipt of the small incentive. Consequentially a down-shift in incentive magnitude following a large number of rewarded trials should produce a greater decrement in performance than would a down-shift following a smaller number of trials. The present experiment was designed to test this prediction. A small reward control group was added for the group receiving the large number of preshift trials. It was felt that if a significant depression was shown it would be exhibited by this group.

Also, in line with frustration theory, it would be expected that the disruption in performance would be observed initially in the goal measure and spread backwards to measures in more remote sections of the apparatus as $\mathrm{r} f-\mathrm{sf}$ generalized backwards.

Subjects. The Ss were 48 male albino rats, approximately 90 days old at the beginning of the experiment, purchased from the Holtzman Co., Madison, Wis. The Ss were housed in individual cages, and maintained on $12-14 \mathrm{~g}$ Purina lab chow per day during the experiment. All Ss were fed 15-30 min following the completion of the daily experimental session. Water was always available.

Apparatus. The apparatus (more fully described in Davis \& North, 1967) was a $4 \mathrm{ft} 10$ in straight runway with a white start box, and black run section and goal box. Photoelectric cells mounted 8 in beyond the start door, and 6 in \& $24 \mathrm{in}$. beyond the first beam yielded a start and two running times, respectively. A fourth timer gave goal times in the 8 in. section in front of the goal cup. A fifth timer gave a total latency from the raising of the start door to the breaking of the last beam in the goal box.

Procedure. The Ss were randomly assigned to two experimental groups and one control group of 16 Ss each. Group E-108 Ss were given 108 training trials with large reward $(8,97 \mathrm{mg}$ Noyes pellets) followed by 63 trials with

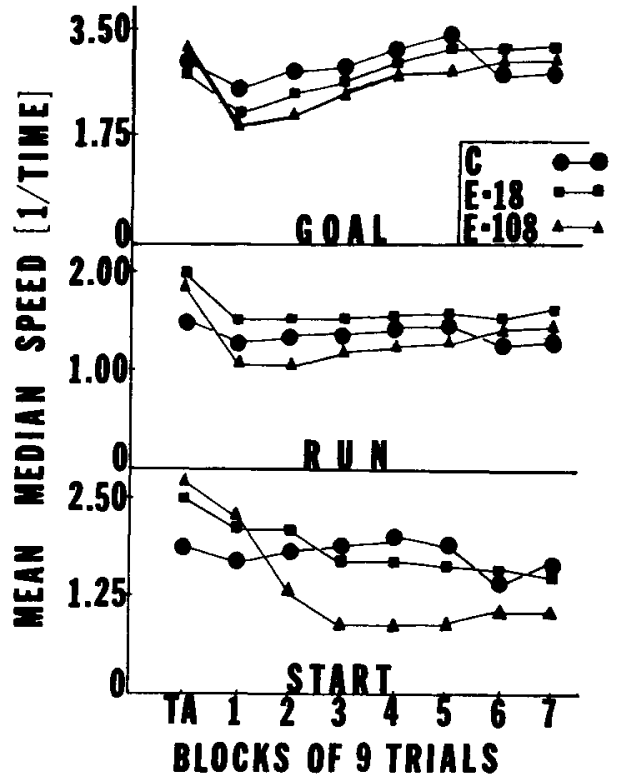

Fig. 1. Mean median speeds at terminal acquisition (TA) and during the incentive reduction phase.

small reward (1, $45 \mathrm{mg}$ Noyes pellet). Group E-18 Ss were given 18 large reward training trials also followed by 63 small reward trials. Group $C$ (control) Ss were given 171 trials with only small reward. The design, showing handling, pretraining, and training trials, is shown in Table 1. Deprivation was begun for all Ss on Day 1.

As can be seen from Table 1, pretraining for Group E-18 was delayed until just before training in order to: (1) make the succession of pretrainingtraining conditions the same for all Ss, and (2) have Group E-18 and E-108 Ss begin the incentive reduction phase at the same time. So that all Ss would receive an equal amount of handling by $\mathrm{E}$, Ss in group E-18 were given daily handling trials, equal to the number of daily trials received by Group E-108 and $\mathrm{C} \mathrm{Ss}$, prior to the beginning of their pretraining phase. A handling trial consisted of placing $S$ into a cardboard box (12 in. X 12 in. X 12 in.) for $15 \mathrm{sec}$ and then returning him to his home cage. Pretraining consisted of handling and taming, habituation to the reward pellets, and habituation to the unbaited apparatus. Ss received three trials per day in all phases of the experiment.

On runway trials, Ss were removed from the goal box as soon as the last piece of food was taken into the mouth. It was felt that this procedure would eliminate the conditioning of any competing responses to the goal box. The daily order for running Ss was randomized. In addition to the latencies that were recorded for each $S$ for each trial, any stops, retraces, urinations, or defecations that occurred were also recorded.

Results. Means of Ss' daily median response speeds over blocks of nine trials for start, run ( 24 in. section), and goal measures at terminal acquisition (TA), and during the incentive reduction phase are presented in Fig. 1.

Table 1

Experimental Design

\begin{tabular}{llllll} 
& Days 1-8 & Days 9-30 & Days 31-38 & Days 39-44 & Days 45-65 \\
\hline Group E-18 & HANDLING & HANDLING & PRETRAINING & TRAINING & $\begin{array}{c}\text { INCENTIVE } \\
\text { REDUCTION }\end{array}$ \\
& & & & & INCENTIVE \\
Group E-108 & PRETRAINING & TRAINING & TRAINING & TRAINING & $\begin{array}{c}\text { REDUCTION } \\
\text { Group C }\end{array}$ \\
\hline
\end{tabular}


Analysis of variance comparing E-108 vs E-18, and E-108 vs C were performed for the start, run, and goal measures. Start speed analyses yielded the following significant results:(1) $E-108$ vs $E-18$, trial blocks $(F=12.61$, df $=7 / 210, p<.01)$, Groups by Trial Blocks interaction $(\mathrm{F}=2.09, \mathrm{df}=7 / 210, \mathrm{p}<.05)$; (2) $E-108$ vs $C$, trial blocks $(F=8.60$, $\mathrm{df}=7 / 210, \mathrm{p}<.01)$, Groups by Trial Blocks interaction $(F=7.15, \mathrm{df}=7 / 210, \mathrm{p}<.01)$. Run speed analyses yielded the following significant results: (1) $E-108$ vs $E-18$, groups by trial blocks interaction $(\mathrm{F}=7.12, \mathrm{df}=7 / 210, \mathrm{p}<$ $.01)$; (2) $E .108$ vs $C$, trial blocks $(\mathrm{F}=5.23$, df $=7 / 210, \mathrm{p}<.01)$, Groups by Trial Blocks interaction $(F=2.83$, df $=7 / 210, p<$ $.01)$. The only significant $(p<.01)$ results yielded by the goal speed analyses were for the trial blocks factor.

The significant interactions obtained for the start and run analyses were investigated further by analyses of the simple main effects. Start speed analyses yielded the following significant results: (1) $E-108$ vs $E-18, \mathrm{TA}$, and trial blocks $2-5(\mathrm{~F}=7.94$, $5.68,7.58,9.41,6.94 ; \mathrm{df}=1 / 30 ; \mathrm{p}<.01, .05, .01, .01$, and .05 , respectively); (2) E-108 vs $C$, TA, and Trial Blocks $1,2,4,5(\mathrm{~F}=$ $24.12,5.65,10.06,19.98,10.79 ; \mathrm{df}=1 / 30 ; \mathrm{p}<.01, .05, .01, .01$, and .01 , respectively). Run speed analyses yielded the following significant results: (1) $E-108$ vs $E-18$, Trial Blocks 1,3 , and $4(\mathrm{~F}=$ $5.18,4.99,4.17 ; \mathrm{df}=1 / 30 ; \mathrm{p}<.05, .05$, and .05 , respectively); (2) $E-108$ vs $C$, TA $(\mathrm{F}=12.38$, df $=1 / 30, \mathrm{p}<.01)$.

Mann-Whitney $U$ tests were used to analyze the stop and retrace data. During the incentive reduction phase Group E-108 showed significantly more stops ( $\mathrm{U}^{\prime}=65.50, \mathrm{p}<.05$; two-tailed), and retraces $\left(\mathrm{U}^{\prime}=40.50, \mathrm{p}<.002\right.$; two-tailed $)$ than did Group E-18.

Discussion. As can be seen from Fig. I a reduction in goal, run, and start speeds followed incentive reduction. There was partial support for the hypothesis, derived from frustration theory, that the maximal decremental effects of incentive reduction would occur first at the goal, next in the run section, and finally in the start box. Goal and run speed decrements reached their lowest levels by the first trial block, whereas start speeds continued to decline until at least the third trial block.

Comparing the incentive reduction performance of groups E-108 and E-18, it can be seen that there was a significantly greater reduction for E-108 than for E-18 in the run and start measures. It is not entirely clear why a significant difference was not obtained in the goal section where the effect, due to theoretically greater frustration for Group E-108, should have been most marked.

The only significant depression effect (E-108 vs C) was obtained in the start measure. Here also, it is not clear why a depression effect was not obtained in the run and goal sections where frustration should have been greater.

It is interesting to note that the results of this study are not inconsistent with Capaldi's (1967) sequential hypothesis, and more specifically the mechanism of stimulus generalization decrement. However, it is obvious that if stimulus generalization decrement is to account for the start and run speed results where Group E-108 fell significantly below Group E-18, one must assume different generalization slopes for the two groups. That is, if the initial pre-incentive reduction habit strength of E-108 were at least as great, or greater than that of E-18, the generalization gradient for E-108 must cross that of E-18 if generalization decrement is to account for these results.

\section{REFERENCES}

AMSEL, A. The role of frustrative non-reward in non-continuous reward situations. Psychol Bull, 1958, 55, 1-3-119.

CAPALDI, E. J. A sequential hypothesis of instrumental learning. In K. W. Spence \& J. T. Spence (Eds.), The psychology of learning and motivation: Advances in research and theory, Vol. 1. New York: Academic Press, 1967. Pp. 67-156.

CRESPI, L. P. Quantitative variation of incentive and performance in the white rat. Amer. J. Psychol., 1942, 55, 467-517.

DAVIS, S. F., \& NORTH, A. J. The effect of varied reinforcement training on behavior following incentive reduction. Psychon. Sci., 1967, 9, 395-396.

DiLOLLO, V. Runway performance in relation to runway-goal-box similarity and changes in incentive amount. J. comp. physiol Psychol, 1964, 58(2), 327-329.

ZEAMAN, D. Response latency as a function of the amount of reinforcement. J. exp. Psychol, 1949, 39(4), 466-483.

\section{NOTES}

1. Supported by National Science Foundation Grant GB 2873 to the second author.

2. Present address: Department of Psychology, Texas Christian University.

3. Present address: University of Texas Southwestern Medical School; Dallas,

Texas. 